\title{
COMPARATIVE STUDY OF DURATION OF ORTHODONTIC TREATMENT AMONG NEPALESE ADOLESCENT AND ADULT PATIENTS
}

\author{
Dr. Prakash Bhattarai ${ }^{1}$, Dr. Rabindra M. Shrestha ${ }^{2}$ \\ ${ }^{1}$ College of Dental Sciences - NMC, Kathmandu \\ ${ }^{2}$ Kantipur Dental College, Kathmandu \\ E-mail: prakashbhattarai@yahoo.com
}

\section{ABSTRACT}

The purpose of this study is to compare the duration of orthodontic treatment among Nepalese adolescent and adult orthodontic patients. A total of 134 adolescent patients and 46 adult patients who have completed the orthodontic treatment from The Orthodontic Center (TOC) were randomly selected. All patients were treated with straight wire brackets. Transferred patients, impacted canine, two-phase treated patients and previous orthodontic treated patients were excluded. The result of the study found that the average duration of treatment for adolescent was 30.38 months while that for the adult was 28.83 months. The independent sample $t$ test revealed that there is no clinical significant difference in adolescent and adult patients in duration of orthodontic treatment

Key words : adolescent, adult, orthodontic, straight wire bracket

\section{INTRODUCTION}

There has been a substantial increase in the proportion of adult patients in orthodontic practice over the last several years ${ }^{1-3}$. According to Thomas M Graber and Rober L Vandarsdall the percentage of adult patients who have received orthodontic treatment has increased significantly from $3 \%$ in 1970 's to $25 \%$ in 1990 's in US. ${ }^{4}$

In Nepal fixed orthodontic treatment was started around 15-20 years back. At that time the treatment was limited to adolescent patients. Due to increasing awareness, economy, availability of orthodontic service and newer technique; Nepalese adult orthodontic patients are increasing day by day. It may also be due to the fact that wearing the braces by an adult is getting more socially acceptable than previously which has made easier for adults to seek orthodontic treatment. $^{5}$

Treatment duration is affected by several variables, such as age (adolescent/adults), sex, extraction/non-extraction modality ${ }^{6}$ missing appointments, breakage of appliance, patient co-operation in wearing of elastic, bite plate etc, Angle's classification of malocclusion, number of dental arch treated, number of treatment phases etc. Most of the authors believed that the duration of orthodontic treatment mainly depends on patients' co-operation. ${ }^{7,8,9}$ There is a clinical myth that adult treatment is more difficult, less effective, and takes longer time than the traditional adolescent treatment ${ }^{10-13}$

The purpose of this study is to compare the duration of orthodontic treatment among Nepalese adolescent and adult orthodontic patients and to evaluate how the adolescent versus adult age factor affects the duration of orthodontic treatment.

\section{MATERIALS AND METHOD}

Biologically an adult is defined as a person who has ceased to grow physiologically which happens by the age of 18 years of age. Concomitantly, 18 years is considered as an adult by census where a person can cast the vote and can take a driving license in Nepal. For this reason; we have categorized adolescence as 11 years to 17 years and adults as 18 years and above.

The inclusion criteria set for the study were the age of the subjects with minimum of 11 years and above, presence of all permanent teeth except third molars and patients with no previous history of orthodontic treatment. The exclusive criteria were patients with impacted canine, incomplete case 
record, two-phase treatment case, transferred cases, multiple missing appointment more than three times or patients who did not turn up since three months.

Out of 200 randomly chosen orthodontic cases of The Orthodontic Center (TOC); 20 cases were discarded because of the exclusion criteria. Thus a total of 180 cases were selected; out of which 134 were adolescent with mean age 13.61years and 46 were adult with the mean age 23.07 years Table I describes the description of the sample based on adolescent and adult age group.

The start of treatment was defined as the date on which first arch wire placement was done and debonding as the date on which fixed appliances were completely removed.
All the duration is converted to nearest of months with decimals

Straight Wire Technique: All subjects were treated with Straight Wire mechanics. The entire appliance had Roth Prescription of tip and torque. All slots were $0.018 \times 0.025$ inch and were placed at right angles to the long axes of the teeth. Both round and rectangular arch wires were used. T loops, L loops, Key hole loops, elastics, headgear, were the routinely used.

Statistical Analysis: All data were fed into SPSS software $13^{\text {th }}$ version. The independent sample t- test was performed. The $\mathrm{t}$ test was used to compare the difference between adolescent and adults. The level of significance was set at 0.05 .

Table I. Sample size distribution

\begin{tabular}{lllllll}
\hline Age group & Number & Minimum age & Maximum age & Range & Mean age & S.D \\
Adolescent & 134 & 11 & 17 & 6 & 13.61 & 1.96 \\
Adult & 46 & 18 & 44 & 26 & 23.07 & 5.52 \\
\hline
\end{tabular}

\section{RESULTS}

The result of the study reveals that the mean duration of orthodontic treatment for Nepalese adolescent patient is 30.38 months while that for adult is 28.83 months. The most relevant data of this study is presented in Table II and Table III

\section{Table II. Duration of Orthodontic treatment (in months)}

\begin{tabular}{lllll}
\hline Age group & Minimum duration & Maximum duration & Mean duration & S.D \\
Adolescent & 16 & 48 & 30.38 & 8.15 \\
Adult & 17 & 47 & 28.83 & 8.33 \\
\hline
\end{tabular}

\begin{tabular}{|cccc}
\multicolumn{4}{c}{ Table III. Statistical test of duration of Orthodontic treatment } \\
\hline Adolescent & Adult & p-value & Significance \\
30.38 & 28.83 & 0.26 & NS \\
\hline (NS-Not Significant) & & & \\
\hline
\end{tabular}

\section{DISCUSSION}

The studies on histological changes during orthodontic tooth movement have revealed a two-week delay in adults to reach a state of cellular proliferation. ${ }^{14}$ This fact has been mentioned by many authors to explain why, in their opinion, adult treatment is less effective and takes longer duration. ${ }^{10,15-17}$ But in our study there is no clinically significant difference in duration of orthodontic treatment between adolescents (30.38 months) and adults (28.83 months). In fact the present finding is exactly opposite to the previous literature which showed that the adult patients took slightly less (1.5 months) duration than the adolescent patients. In Nepalese context, this may be due to the fact that food habit of Nepalese is very fibrous and course as compared to the western society and especially the adolescent patient will not resist to such food than the adult patients, resulting in recurrent bond failure and eventually longer duration of orthodontic treatment. Additionally, adult patients are more compliant and much cooperative in wearing elastic, bite plate etc; they arrive to the clinic on time and do not generally miss appointments. 
Dyer $e^{2} a^{18}$ have clearly quoted that the adult treatment does not necessarily equate to a longer duration of treatment. He found the treatment duration of adolescent and adult were 2.46 years and 2.56 years respectively. Similarly, Stuate et al ${ }^{19}$ also found no statistically significant difference between adolescent and adult treatment effectiveness and duration. It may be a clinical fact that there is no difference between adolescent and adult treatment duration as adult patients are generally more compliant, motivated and follow prescribed mechanotherapy very well. ${ }^{20}$ According to Alexender ${ }^{21}$ adult patients are more cooperative also maintain oral hygiene properly which causes teeth to move faster in healthy periodontium.

Thus it is important to note that the two-week delay in adults to reach a state of cellular proliferation is probably of no clinical importance over a 29 month long period of orthodontic treatment.

\section{CONCLUSION}

The average duration of orthodontic treatment for Nepalese adolescent patient is 30.38 months while that for the adult is 28.83 months. The independent sample $t$ test revealed that there is no statistically significant difference in adolescent and adult in duration of orthodontic treatment.

\section{ACKNOWLEDGEMENT}

The authors heartily acknowledge Mr Prem Prasad Pant of Nepal Medical College for his help in statistical analysis procedure of the study.

\section{REFERENCES}

1. Williams RL, Shilliday DJ, Kress W: The American Association of Orthodontists study of the availability of orthodontic services. AM J ORTHOD 1975;68:326-38.

2. Gottlieb EL, Vogels DS: 1983 JCO orthodontic practice study. Part I. Trends. J Clin Orthod 1984;18:167-73.

3. Gottlieb EL, Vogels DS. 1983 JCO orthodontic practice study. Part II. Practice success. J Clin Orthod 1984;18:247-53.

4. T M Graber: Orthodontics principles and practice $3^{\text {rd }}$ ed. W. B. Saunders Corporation 2005 P.516

5. W R Proffit: Contemporary Orthodontics $2^{\text {nd }}$ ed. Mosby year Book Inc 1997 P.15

6. Bhattarai P., Shrestha RM: Comparison of duration of orthodontic treatment with and without extraction among orthodontic patients. JNDA 2009:10:119-121

7. Allan TK, Hodgson EW: The use of personality measurements as a determinant of patient cooperation in an orthodontic practice. Am J Orthod 1968;56:433-40.

8. Starnbach HK, Kaplan A: Profile of an excellent orthodontic patient. Angle Orthod 1975;45:141-5.

9. Slakter MJ, Albino JE, Fox RN, Lewis EA: Reliability and stability of the orthodontic patient cooperation scale. Am J Orthod 1980;78:559-63.

10. Bond JA: The child versus the adult. Dent Clin North Am 1972;16:401-12.

11. Weiss RC: Physiology of adult tooth movement. Dent Clin North Am 1972;16:449-57.

12. Chiappone RC: Special considerations for adult orthodontics. J Clin Orthod 1976;10: 535-45.

13. Barrer HG: The adult orthodontic patient. Am J Orthod 1977;72:617-40.

14. Reitan K: Tissue reaction as related to the age factor. Dent Rec 1954;74:271-9

15. Weiss RC: Physiology of adult tooth movement. Dent Clin North Am 1972;16:449-57.

16. Chiappone RC: Special considerations for adult orthodontics. J Clin Orthod 1976;10: 535-45.

17. Barrer HG: The adult orthodontic patient. Am J Orthod 1977;72:617-40.

18. Dyer GS, Harris EF, Vaden JL: Age effects on orthodontic treatment: adolescents contrasted with adults. Am J Orthod Dentofacial Orthop 1991;100:523-30.

19. Stuart I. Robb, Cyril Sadowsk: Effectiveness and duration of orthodontic treatment in adults and adolescents. Am J Orthod Dentofacial Orthop 1998:14:383-386.

20. Musich DR: Assessment and description of the treatment needs of adult patients evaluated for orthodontic therapy: characteristics of solo provider group. Int J Adult Orthod Orthog Surg 1986;1:55-67.

21. RG Wick Alexender: The Alexender Dicipline. Ormco Corporation 1982 Page 300 